\title{
What can we learn from empirical studies about piracy?
}

\author{
Sylvain Dejean \\ University of Rennes 1 \\ Faculté des Sciences Economiques \\ 7 place Hoche - CS 86514 \\ 35065 RENNES cedex - France \\ sylvain.dejean@univ-rennes1.fr
}

\begin{abstract}
The purpose of this paper is to make an assessment of the empirical literature on the consequence of piracy on the cultural industry. The diversity of data collected and methodology used by empirical studies make the comparison of the literature results difficult. On the one hand some studies seem to have overestimated the impact of digital piracy, due, for example, to the use of Internet access as a proxy for piracy. On the other hand the problem of finding a good instrument to avoid the endogeneity between files illegally downloaded and goods purchased has probably led to an underestimation of the impact of piracy. As a result, the major finding of empirical works about piracy could be the change in the role of industry actors which modify the way cultural goods are consumed and produced. We also discuss the conclusions that can be drawn from the different evolution of the revenue of the music and the movie industry since the appearance of the first P2P network.
\end{abstract}

JEL classification: L82, L86, K42

Keywords: Cultural industry, File-sharing, Piracy

\section{Introduction}

Even if it is difficult to date the birth of the cultural industry, it is impossible to dissociate it from technical discoveries which allow the constant improvement of reproduction process. The development of copier, gramophone record, magnetic tape and more recently computer science has steadily decreased the cost of reproducing cultural goods ${ }^{1}$ and enhanced the quality of listening watching and reading experience. Since the generalization of home computer and the fast development of the Internet, the cultural industries have lost their

\footnotetext{
${ }^{1}$ In this paper we call cultural goods, goods that could be reproduced and are subject to copyright.
} 
ability to control the reproduction of cultural products. Peer to peer (P2P) networks are the virtual place where it becomes possible to freely share everything which could be digitalized. The low bandwidth proposed by first Internet access providers makes music the most exchanged type of cultural goods on P2P networks, but broadband access and improvement in the encoding format of digital files recently generalized the sharing of movies, software and video games.

Since the end of 90's the music industry has known an important decline of its revenue which decreased in the US by 28\% between 1999 and 2007 (see figure 1). An intensive lobbying effort has been done by the music industry to convince the legislator and the public opinion that P2P networks were responsible for the fall of CD sales.

Following the claim of the music industry, we could expect that the development of broadband access and the improvement in P2P protocol cause the same trouble to the movieindustry. Surprisingly, the evolution of revenues in different fields of this industry shows slightly different trajectories (see figure 2). The relative good health of the market for movies leads to consider a more balanced relationship between piracy and cultural industry. Either there exists characteristics specific to the movie industry that make piracy having a positive impact on the profit of suppliers or the negative impact of piracy is lagged due to the slow generalization of downloading movies.

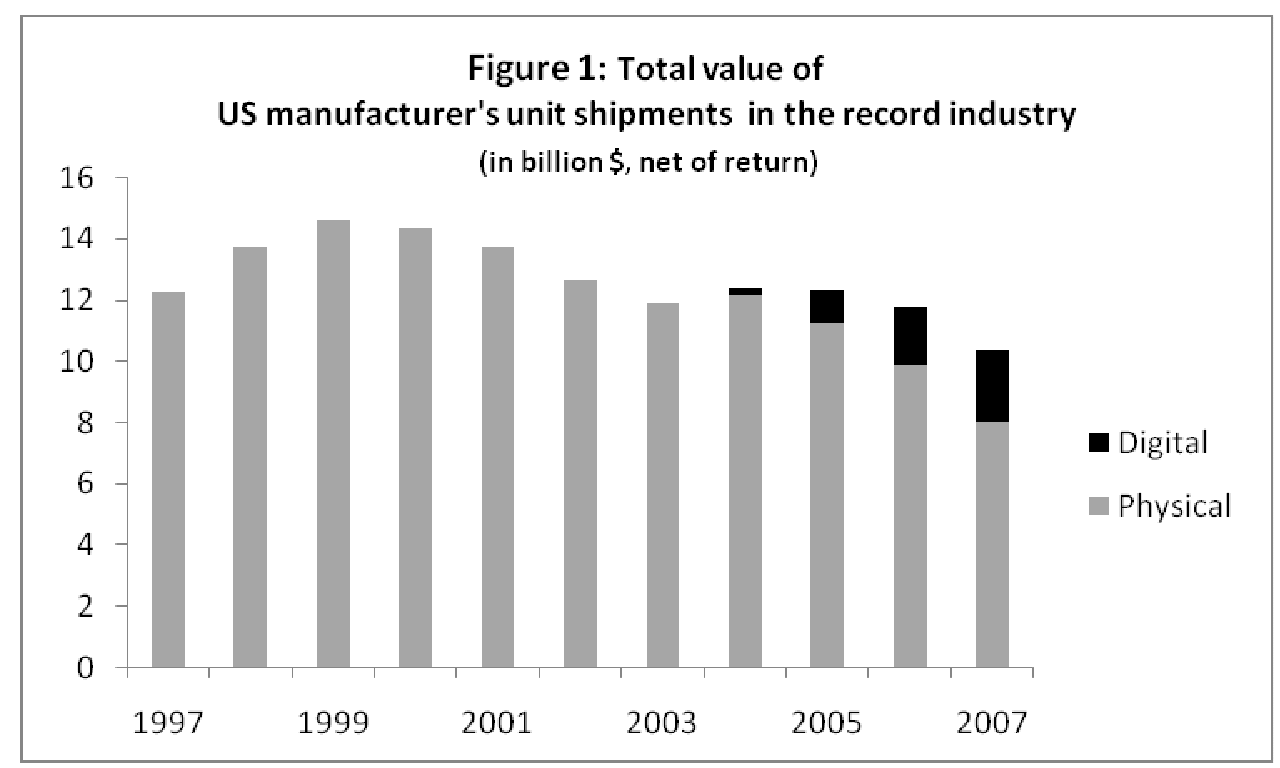

Economists were engaged in the debate and an important number of articles were devoted to the problem of digital piracy. Because of the lack of data at the beginning of the phenomenon, a large part of the literature was dedicated to theoretical aspects of the consequence of 
copying. If the conventional wisdom states that the development of copying technology harms the demand for originals and decrease the long-term supply (Johnson, 1985), different papers show that there exists conditions under which piracy could increase the profit of the firm.

1) If the supplier of originals can discriminate between those who use it to generate copy and those who do not, indirect appropriability suggests that the price of originals rise, internalizing the cost of the potential copies (Besen and Kirby, 1989, Liebowitz, 1985, and Ordover and Willig 1978).

2) If the good supports network effects, its value rises with the install base of users. It could be profitable for the supplier to accommodate for a number of illegal copies in order to increase the willingness to pay for original (Conner and Rumelt, 1991, Takeyama, 1994).

3) The asymmetric information between producers and consumers of cultural goods make the piracy able to provide the missing information (Duchêne and Waelbroeck, 2006, Takeyama, 2003, Peitz and Waelbroeck 2006b). The so called "sampling effect" produces a better matching between the consumer desire and the variety of goods proposed. The supplier is able to take advantage of this effect as consumers have a higher willingness to pay for a product which perfectly matches with his preference.

Most of the time only 3) can be observed in empirical studies related to the consequence of digital piracy on music and movie industries. Indeed, indirect appropriability needs to control the number of copies made from the original which is impossible with digital and costless reproduction technology as a copy can be done from another copy. Contrary to software, the utility that could be derived from listening music or watching a movie is not directly linked to the number of people who make the same consumption decision. Indirect network effects can anyway be considered and take the form of fashion effects, reputation mechanism and word of mouth (Awad et al., 2004, Moul, 2007) but won't be discuss in this article as to our knowledge, except for software (Givon et al., 1995 and Brynjolfsson and Kemerer, 1996), no empirical evidence show that network effects induced by piracy have an impact on cultural industry revenue.

The purpose of this paper is to make an assessment of the empirical literature on the impact of piracy on the revenue of cultural industry. The diversity of empirical studies methodologies make impossible to run a meta-analysis, as a consequence we achieve a second best objective by discussing results of the literature according to the nature of the data collected, the field of the experiments, as well as proxy and dependent variable used. 
Some reviews of the literature are already available as the one of Peitz and Waelbroeck (2006a) who focus on theoretical aspects, Liebowitz and Watt (2006) report the consequence of copyright infringement on the music industry and discuss possible alternatives to finance creative industries. To our knowledge two papers review some of the empirical findings of the literature, Png (2006) who more broadly focuses on the impact of copyrighted law and Waelbroeck (2006) who analysis some aspects of early empirical studies.

This paper differentiates from the previous states of the art as we compare conclusion drawn from the consequence of piracy, on the music and the motion picture industry. We also propose a better understanding of the consequence of "digital revolution" as we find evidence in the literature that piracy has forced the transformation of the production, distribution and consumption of cultural goods.

The remainder of the paper proceeds as follows: section 2 deals with the difference between physical and digital piracy. Section 3 reviews the consequence of digital piracy on music and video industry. Section 4 suggests new interpretation of the consequence of piracy on the cultural industry. Section 5 concludes and opens new lines of research.

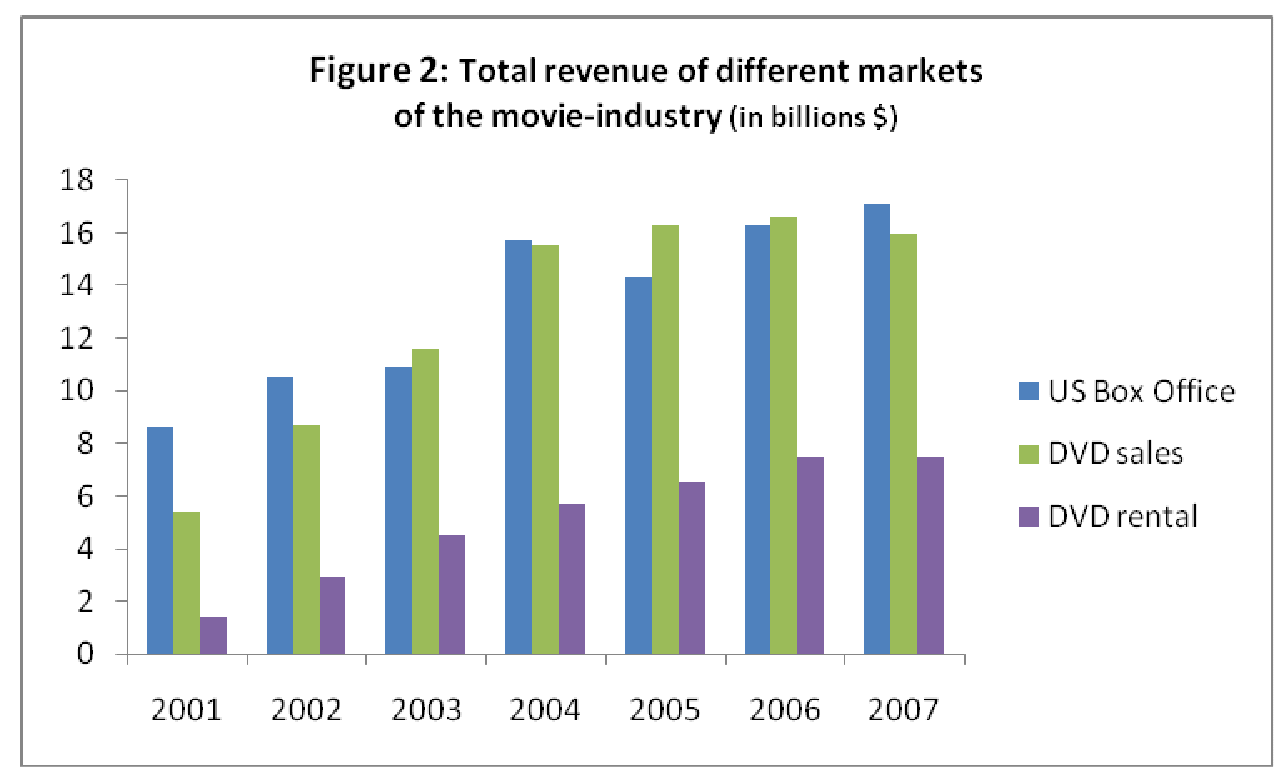

\section{Different types of piracy}

Almost every studies which evaluate the impact of piracy on the cultural industry revenue conclude that illegal reproduction harms the profitability of copyright owners. However two types of piracy should be distinguished: the hard goods piracy which refers to the illegal reproduction of physical product as music CD, DVD video or software and the digital piracy 
which is the diffusion of digitalized cultural goods ${ }^{2}$ over the Internet using sharing communities.

\subsection{Hard goods piracy}

The rate of hard goods piracy is mainly correlated to socio-economics characteristics. In a cross national study, Husted (2000) shows that software piracy rates is negatively correlated with GDP per capita, income inequality and individualism. Bezmen and Depken (2006) obtain the same result inside United-states, they find that a $1 \%$ increase in per capita income lead to $0.25 \%$ decrease in the software piracy rate. Kranenburg and Hogenbirk (2003) for different industries of entertainment, as well as Banerjee et al. (2005) for the software industry emphasize that political regimes, economic instability and institutional factors are associated with higher revenue losses due to illegal copying. Hard goods piracy competes directly against the cultural industry by organizing the production and the distribution of counterfeit goods. As these copies physically exist they can be observed or seized and allow an estimate of their diffusion. The motion picture association argues that US studio lost $\$ 6.1$ billion because of piracy in 2005, $62 \%$ of this loss results from hard goods piracy. The market of China, Russia and Thailand are respectively composed of $90 \%, 79 \%$ and $79 \%$ of counterfeit goods ${ }^{3}$. For the IFPI $37 \%$ of music discs purchased around the world are an illegal copy $^{4}$, and organized crime is responsible for a large share of illegal copy distribution ${ }^{5}$.

Hui and Png (2003) conduct a cross national study on the impact of music piracy over the demand for recorded music. Their data were collected in 1998 which ensure that file-sharing piracy can't explain the result of their regression analysis. They estimate that piracy reduced sales by $6.6 \%$ which only explains a part of the "official" loss incurred by the music industry during the same period.

\subsection{The difficult measurement of digital piracy}

The second type of piracy, appeared in 1999 with Napster, is commonly named file-sharing. Contrary to hard goods piracy, this activity is mainly end-user oriented. Three differences arise from the use of internet for sharing copyrighted contents and make their measurement difficult.

\footnotetext{
${ }^{2}$ To allow their diffusion over the Internet cultural goods are usually compressed in loose quality format as MP3 for music AVI for video or RAR for data.

${ }^{3} \mathrm{http}: / /$ www.mpaa.org/leksummaryMPA\%20revised.pdf

${ }^{4} \mathrm{http}: / /$ www.ifpi.org/content/library/piracy-report2006.pdf

${ }^{5} \mathrm{http}$ ://www.ifpi.org/content/library/music-piracy-organised-crime.pdf
} 
First, P2P involves a decentralized structure of piracy which means that each individual is able to act as the supplier and/or the end-user of an illegal copy. It makes the struggle against piracy more difficult because the distribution of copy doesn't depend on a particular group or individual $^{6}$.

The second difference deals with the digitalization of information exchanged on $\mathrm{P} 2 \mathrm{P}$ networks. The individuals share contents extracted from their physical support which permit to listen music or watch a film on any compatible device as well as modify or combine it with another file. According to Gensollen (2006) digital economics make more complex the consumers production function by changing information to an intermediate good. As a result it becomes difficult to know what is observed on a P2P network as well as where are the limits of copyright law.

Third, the principle of net neutrality which forbids broadband carries to discriminate against contents or users is a major concern for cultural industries ${ }^{7}$. It doesn't allow to filter particular content and is a guarantee of the free development of P2P networks and open source activities.

As a consequence, the decentralization of pirate networks, the complexity of consumption process and content discrimination make digital piracy and its consequences difficult to estimate and require most of the time indirect measure of this phenomenon.

\section{The questionable relationship between file-sharing and cultural industry revenue}

Even if developing countries exhibit the highest piracy rates in term of market share held by counterfeit industry, they don't represent the biggest dollars lost for cultural industry. For the Motion Picture Association (MPA) members, countries where the revenue loss is the most important are the US, Mexico, UK and France. That's why cultural industries pay so much efforts to enforce copyright infringement law as digital piracy is a matter of concern for developed countries and represents a potential displacement of the demand in mature and profitable markets.

Empirical studies which estimate the impact of digital piracy first focused on the music industry ${ }^{8}$ but recently some studies have took an interest in the consequence of piracy on the movie industry which allow to compare the consequence of piracy in different contexts.

\footnotetext{
${ }^{6}$ It leads the RIIA to choose at random the Internet users that have been suited.

${ }^{7}$ http://www.riaa.com/newsitem.php?id=445DBB88-3C46-F2B7-784F-8B1B1B7F5FAA

${ }^{8}$ The reason is straightforward, the size of a compressed music files don't exceed some megabits and could be download in few minutes with standard Internet access. The download of movies software and video games became possible with the generalization of broadband access.
} 


\subsection{Is Internet and broadband penetration rate a good proxy for digital piracy?}

Two panel-based studies (Liebowitz, 2008 and Zentner, 2005) use Internet and broadband access as the proxy for measuring the level of digital piracy. Zentner (2005) exploits a panel of 65 countries during the period 1997-2002. The author estimates the reduction in music sales between $6 \%$ and $9 \%$ for an average level of broadband penetration. Liebowitz (2008) controls for differences in countries specific characteristics by taking American cities as the unit of analysis. Every specifications chosen by the author lead to a strong negative correlation between broadband access and change in album per capita. The average coefficient associate with the impact of broadband penetration is twice the level observed in 2003.

The main criticism that can be done to these studies is the use of a "black box" to approximate the impact of the downloading of music files. With the rising of the Internet, new activities emerged. They' are more or less time consuming but represent good alternatives to substitute for previous entertainment activities. According to EIAA studies ${ }^{9}$ downloading music is only the fifth most popular online activities across Europe in a tie with listening to webradio (31\% of interrogated people). People also use the Internet to search for information, send e-mail, going and contributing to an online community (forum, wiki, socialnetwork), develop and maintain blog or personal homepage, watching TV, films and videoclips in streaming media ${ }^{10}$. Another report from EIAA ${ }^{11}$ confirms that families who make online activities consume less other media as TV, books, newspapers, radio. It supports the claim that multiple Internet usages change the way people consume and use medias and cultural goods. Seung-Hyun (2007) also shows how the decrease of consumption in a variety of entertainment goods corresponds with the rise of the Internet.

As a consequence it becomes difficult to estimate the share of illegal music download in online activities which is responsible for the decline in music sales. Liebowitz (2008) and Zentner (2005) probably overestimate the impact of file-sharing on the recording industry but certainly emphasized the impact of the new consumption behaviours allowed by the development of the Internet.

\footnotetext{
${ }^{9} \mathrm{http}: / /$ www.eiaa.net/news/eiaa-articles-details.asp?lang=1\&id=154

${ }^{10}$ Of course all these activities have evolved since the beginning of the Internet and were not necessarily available during the period studied by the authors .

${ }^{11} \mathrm{http}: / / w w w . e i a a . n e t / F t p /$ casestudiesppt/EIAA\%5FDigital\%5FFamilies\%5F2008\%2DExecutiveSummaryFINA L 7\%2E4\%2Epdf
} 
Peitz and Waelbroeck (2004) conduct a cross-section analysis for 16 countries over the period 1998-2002, they conclude that online piracy would be responsible for a $20 \%$ decrease in music sales. As the previous authors they use the percentage of home broadband connexion in their regression but capture the impact of digital piracy by the percentage of people who declare having downloaded a MP3 file at least once. Their results show that the coefficient associated with broadband connexion is three times more important than the percentage of downloader and seems more robust to different specifications. It gives additional reasons to be cautious in selecting the development of broadband access to explain and estimate the revenue decline of a cultural industry.

An alternative suggestion is proposed by Liebowitz (2007a) which studies the interaction between radio usage and variation in record sales. As the music industry usually exploits radio station to promote and advertise their cultural productions, one could expect that a positive correlation links the use of music radio station and the consumption of recorded music. Surprisingly the opposite result appears in the regression, suggesting that listening to music radio is a substitute for buying recorder music.

This result takes on a new perspective in the light of the success of webradios and podcasts. Contrary to FM broadcast band the Internet imposes no limit in radio diffusion which allows the development of a couple of thousand new medias. The Internet users can choose in a range of diverse and highly specialized digital channels according to his taste or preference. There is little doubt that the way Internet users listen to music online has an impact on the probability to buy music offline. It gives incentives to provide empirical research on new forms of online behaviour and their overall impact on the cultural goods industry.

Boorstin (2004) is the first author who reports a positive relationship between Internet access and CD sales, his study focuses on American cities during the period 1998-2001. Boorstin (2004) shows that the impact of file-sharing varies with the age group of users. Indeed while the groups aged less than 24 years use file-sharing to displace the music they usually purchase, the remaining users (more than 24 years) exhibit a complementary relationship between Internet access and CD purchased. The practise of "sampling" would be responsible for the behaviour of older users and the overall effect on $\mathrm{CD}$ sales remains positive as the buying power of the older group exceed the one of the younger group ${ }^{12}$. Liebowitz (2005)

\footnotetext{
${ }^{12}$ Liebowitz (2008) find a quite similar result, showing that cities with a larger share of users aged 10 to 29 lead to higher negative impact of Internet access on album sales per capita.
} 
reveals several problems in the specification of the model ${ }^{13}$ and once he has corrected for these errors the overall impact of Internet access on the CD sales appears negative. Despite the correction of Liebowitz, the results still show evidence that getting an Internet access is associated with higher CD bought for users aged more than 25 years. This study gets credit for highlighting the existence of a statistical positive correlation between a particular group of Internet user and the purchase of recorded music. However it remains difficult to estimate the share of this result which is due to income, generational consideration or ability to use $\mathrm{P} 2 \mathrm{P}$ software.

To our knowledge few studies focus on the impact of broadband penetration on the movie industry. However Smith and Telang (2006) provide an interesting result studying the consequence of digital piracy on DVD sales during the period 2000-2003. Their regressions based on regional data suggest, in their more pessimistic specification, that the rise of the Internet and broadband access is responsible for $9.3 \%$ of DVD increases. Even if downloading movies is became easier and faster after 2003, involving the need to confirm and update this result with data based on recent years, the fact that broadband access could have opposite effects on music and movie industry illustrates the complex relationship between files-sharing and consumption of cultural goods. It could also lead to a search for alternative explanations to the decrease of music industry revenue.

\subsection{Measuring users activities on P2P networks}

To avoid the problem raised by the use of the Internet access as a proxy for file-sharing, some economists attempt to collect direct measure of data transferred on P2P networks. An accomplished study based on real data of P2P activities was carried out by Oberlhozer and Strumpf (2007). Collected from two OpenNap servers, the data represent downloads and sales of over 10000 songs and albums during 17 weeks in the US from September 8 to December 31, 2002. Their results show that the number of downloads has no significant effect on album sales. The main difficulty the authors have to face with is the fact that downloads and sales could be determined by the same factors as, for example, the ex ante popularity of artists.

\footnotetext{
${ }^{13}$ Boorstin (2004) don't control for the difference in income between younger and older group of Internet users which could explain why older group of Internet users buy more music than younger group. The second important problem comes from the introduction of a dummy for years 2000 and 2001 which signals the beginning of the age of file-sharing. According to Liebowitz (2005), this dummy interferes with the "piracy effect" already present in the internet access variable.
} 
Oberlholzer and Strumpf use the German holiday period as an instrument which only impact the number of downloaded completed by US users. According to the authors when German kids spend more times on their computer they enhanced the speed and the availability of music files for US downloader. Their two stages least square regressions show that this instrument is highly predictive of the intensity of download which in turn is not correlated with album sales.

The last part of their article brings additional support to the claim that file-sharing is not responsible for the decline in music sales. The authors test and reject four assumptions that presumably link download and sales:

1) The seasonality of file sharing in the US, which decreases during the summer because students are away for the broadband connexion of their campus should induce an increase of sales at the same period? ${ }^{14}$

2) Because of time zone difference East-cost downoladers are more able to take advantage of Western Europe user's availability than west-cost downloaders. As a consequence the decrease in album sales would be higher in the West-cost of the US?

3) Music genres that are heavily downloaded should be the most impacted by decline of sales.

4) The growth of file-sharing users in the US must be correlated with album sales.

Despite the originality and the academic success of this study two questions remain. First, we could ask if the data collected from two OpenNap servers are representative of the whole P2P network? The issue is as much relevant as during the period studied by the authors the FastTrack network (and the famous client Kazaa) is the most successful and used network. Furthermore many OpenNap servers have been shutdown during the collapse of Napster and the anti-piracy crusade of the RIAA, which reduce the attractiveness of this network during the period studied.

Secondly the use of German holiday period as an instrument to explain the number of US download is quite surprising and the robustness of this result to alternative instruments would be a good support for the claim that file-sharing is not responsible for decline in music sales. Blackburn (2007) overcomes the lack of Oberlhozer and Strumpf paper. The author uses data of music download collected from the 5 major P2P networks (including FastTrack) which ensure a better representation of the whole P2P activity. The second major improvement as compare to Oberholzer and Strumpf study is the use of a more intuitive instrument to avoid the endogeneity bias between downloads and sales. Blackburn (2007) considers the role

\footnotetext{
${ }^{14}$ Liebowitz (2007b) criticizes this assumption (and others) because this argument contradicts the main instrument of their regression which specifies that holidays amplify the use of file-sharing in Germany.
} 
played by RIAA announcements in P2P network activity. The authors shows that the RIAA statement of suing individuals who share copyrighted contents is associated with a decrease of P2P network activity while a second announcement that only the heaviest downloader will be taken to court raised the number of sharers and downloaders. Up to this point, Blackburn's result is consistent with the one provided by Oberlhozer and Strumpf (2007) but differentiating the marginal effect of file-sharing according to the popularity of artists lead to a new conclusion. The ex ante unknown artist benefit from the file-sharing while the most popular artists suffer from a decrease in album sales. As the popular artists sale more album than the less popular ones the overall effect of file-sharing turn out to be negative. The author's calculus show that a reduction of $30 \%$ of files available on P2P networks would increase the music industry revenue by more than $\$ 260$ million. Blackburn (2007) exhibits two different aspects of P2P networks: on the one hand he confirms the harm made by digital piracy on the music industry. On the other hand he shows that file-sharing could have a positive impact on unknown artist by allowing them to build a reputation and meet an audience without the help of the record industry.

In addition to their first study Smith and Telang (2008) collect data on the availability of movies on the Bit Torrent network and measure their impact on DVD sales during eight months between 2005 and 2006. Again the authors find no significant effect of file-sharing on the consumption of DVD but they also underline, in a more general way, the complementary relationship between free content distribution ( $\mathrm{TV}$ and cable broadcast as well as P2P network) and the sale of DVD. Their data show that TV and cable broadcast stimulate digital piracy as well as DVD sales without substituting a sale by a download, which suggest that there exist two distinct demands, one for the DVDs and one for pirated movies. This is probably the most striking difference between music and video industry as physical goods produce by record companies fail to compete with digital files provided by P2P networks. This suggestion is based on the tree following arguments.

1) It remains difficult to find a high quality copy of a particular movie. An interesting experimentation made by Fetscherin (2004) who downloads movies on Kazaa during four months between 2002 and 2003, show that only 7\% of files downloaded provide a high quality copy. $40 \%$ of downloaded initiated fail to complete, $33 \%$ can not be played on the computer and $20 \%$ of movies were of poor quality. Note that Kazaa was mainly used for sharing music file and Edonkey or Kad networks as well as the Bit Torrent protocol are more 
efficient in the provision of pirated movie. As a consequence the result of Fetscherin (2004) surely underestimates the performance of actual P2P networks.

2) Due to the size of digital files, even with DSL broadband access, the cost of downloading a poor quality movie is higher than the one of downloading a poor music file

3) DVD contains additional information as bonus, making-of, games which increase the quality difference between files available on file-sharing network and DVDs. The Storage constraint of CD or the implementation of Digital Right Management are probably reasons that enabled record companies to maintain or increase the willingness to pay for physical goods.

An empirical study of De Vany and Walls (2007) bring a different point of view of the impact of file-sharing on the movie industry. Author's paper shows that digital piracy is a major threat for the US motion picture companies and studios. Their estimates conclude that due to digital piracy the revenue of a widely-released movie ${ }^{15}$ has been reduced by $\$ 41.7$ million. This result and its underlying message sound strange because contrary to music industry, US and worldwide box office revenue have never been so high than in $2007^{16}$. The model chosen take a somewhat simple form as the variation in revenue only depend on the number of copy available in P2P network and the week of the run. This paper have to deal with fallacy of composition, as the authors draw general conclusion about file-sharing, only considering the case of a particular movie. Indeed others explanatory variables, not taken into account, can explain a decrease of revenue overtime like the quality of the movie, the competition during the week of run or the number of copy still available on theater each week.

As could be expected a strong negative correlation links the loss of theatrical revenue and the number of copy available on P2P networks but the causality is less obvious. As the revenue decline we can suppose that the number of theater showing the movie decline too. It could lead to an increase of the number of files on P2P networks because it remains the only way to see the movie or because it small success make the low willingness-to-pay consumers more disposed to see a DIVX copy than going to theater. To sum up, the use of an instrument to avoid the endogeneity problem as well as a cross sectional study which allows to consider the role of movie characteristics on the decline of revenue theater would be a good improvement in the understanding of the impact of digital piracy on theatrical revenue.

\footnotetext{
${ }^{15}$ Because of the confidentiality of data used, the name of the movie remains unknown, but one could guess that a blockbuster movie is in question

${ }^{16} \mathrm{http}: / /$ www.mpaa.org/2007-Theatrical-Market-Statistics.pdf
} 
The third source of information in the empirical literature about piracy came from individual survey. The advantage of these studies is to take a closer look to the behaviour pattern of individuals and their motivation to use digital piracy

\subsection{Survey-based study: understanding user behaviour}

Zentner (2006) uses responses to a questionnaire completed by a representative population in 7 European countries. The author clearly shows that people who regularly download music over the internet buy more CDs than others which strengthen the idea that not just substituting effect is underlying the downloading of music files. If it was the case, low willingness-to-pay consumers would probably be more P2P-intensive users ${ }^{17}$. By instrumenting the number of people who declare downloading by the broadband Internet connexion, the author estimates that the use of $\mathrm{P} 2 \mathrm{P}$ reduces the probability to purchase music by $30 \%$ and decreases the sales of the music industry by $7.8 \%$ in the year 2002. However this last result don't take into account information on the quantity of music purchased and downloaded, the author also have to make strong assumption about the homogeneity of consumption amount to estimate an overall effect of piracy on the music sales.

Based on a survey of 500 students across various American University, Rob and Waldfogel (2006) come essentially to the same conclusion, finding that each album downloaded reduces the sales by 0.2 unit. Rob and Waldfogel's main contribution is the carrying out of a welfare analysis which permits to focus on a different aspect of the consequence of digital piracy. The authors show that downloading leads to a reduction in the deadweight loss and consumer expenditure which respectively result in two-thirds and one-third of the welfare per capita increases. When asking to the undergraduates the ex ante valuations of albums they have downloaded and purchased, Rob and Waldfogel (2006) show that the average value assigned to music downloaded is $\$ 10.6$ against $\$ 15.9$ for music purchased. Following the authors if we consider that the average price of an album is $\$ 13$, it means that, in average, undergraduates download music they would have not purchase otherwise. Of course considering the entire distribution of ex ante valuation of music downloaded, and not only his average, make the piracy causing harm to music industry but some aspects of this study confirm that thanks to piracy people are able to sample or discover music that anyway won't be purchased. Another survey, based on French undergraduate students by Bounie et al. (2005), reports two distinct types of behaviour. $30 \%$ of students are "pirates", who have decreased the number of CD

\footnotetext{
${ }^{17}$ We have to note that many theoretical frameworks based on the consequence of piracy are based on the assumption that low willingness-to-pay consumers are those who are more able to use illegal copying.
} 
purchased and have, for the larger part, a low willingness-to-pay for music. The second type of P2P users are "explorers", account for $15 \%$ of responders and are more intensive buyers of music. The particularity of the population questioned make the result of Rob and Waldfogel (2006) and Bounie et al. (2005) not easily generalisable to estimate the global impact on the music industry.

Two studies based on the same survey reporting the household expenditure of US population are made by Michel (2006) and Seung-Hyun (2005), they use difference-in-difference estimators to estimate the change in the household expenditure on music according to the ownership of a personal computer during the pre and post Napster period (1998-2003). Michel (2005) considers a reduction of 13\% of album sales whereas Seung-Hyun (2005) make Napster responsible for $20 \%$ of sales decline. These two studies suffer from the same weakness as those which use the broadband access to approximate the downloading on $\mathrm{P} 2 \mathrm{P}$ networks. Even if individuals who use P2P networks necessarily own a computer the opposite could not be true as many computer-oriented activities could substitute to the listening of music $^{18}$.

To our knowledge there is only one study based on a survey which find no direct relationship between the use of P2P platform and music sales. Andersen and Frenz (2008) exploit a survey representative of the Canadian population, their regressions consider the overall population and a sub-sample of $\mathrm{P} 2 \mathrm{P}$ users. If no correlation exists for the overall population, file-sharers seem to have a positive impact on the CD purchased. Unfortunately the authors only propose a single equation methodology and can't deal with the fact that downloading and sales could be determined by the same omitted variable, the absence of instrument weakens the scope of this result.

The survey analysis focused on the video industry lead to more balanced results than the articles of Smith and Telang (2006, 2008). Following Bounie et al. (2006) the effect of piracy on the movie industry differs according to the mode of movies consumption. Their findings suggest that digital piracy don't reduces theater attendance but display a negative impact on the DVD sales and video rentals. This result is not surprising if we consider that a movie released in theater and a movie downloaded on a P2P network imply very different consumption and can't compete on the demand side of a particular movie. With the

\footnotetext{
${ }^{18}$ Moreover at the end of the 90's music piracy was mainly led by hand-to-hand piracy arising from the commercialization of $\mathrm{CD}$ writers and explains a part of the piracy effect when considering the ownership of personal computer as a proxy.
} 
development of broadband access and more efficient P2P protocol it is now possible to rip and share a DVD in looseless quality with almost no difference with the original source. As a consequence, a population who develops strong competencies and abilities to use P2P network is more likely to substitute video sales and rentals for downloaded files.

This last assertion is partially confirmed by Rob and Waldfogel (2007) ${ }^{19}$ who show that when the first (second) viewing is an unpaid consumption the sales are reduced by $1(0.2)$. Their data also reveal that unpaid consumption, being the first or the second, represents a minor percentage of the total student consumption. It gives explanation why studies based on sample representative of the whole population (and not only students) find no significant decreasing relationship between piracy and video consumption. But according to the authors it's highly plausible that the generalization of broadband access and the enhancement of encoding quality will increase the negative impact of piracy on the movie industry.

The second important feature of Rob and Waldfogel (2007) is that students were questioned about their consumption of the 50 most popular movies during the past tree years. By only focusing on the impact of unpaid consumption on the biggest box office success, the authors probably can't take into account one of the major consequence of the file-sharing revolution. Indeed, with the rising of the Internet, the cultural industry not only lost a part of its revenue but also its ability to select, promote and impose cultural production of its choice. Some evidence of this change and its implication for artists and producers are described in the empirical literature dedicated to piracy.

\section{The long tail and the end of the star system}

According to Chris Anderson (2006), the Internet, by lowering the search and storage costs, has broken the established equilibrium and allows the production and the diffusion of specific and rare contents. The aggregation of demand for goods which belong to niches permits to raise the profitability of products which were not available in traditional distribution networks (Brynjolfsson et al., 2007, Brynjolfsson et al., 2003). The long tail describes the way the supply of contents is no more constraint by the power law distribution of sales.

Indeed, the cultural industries are a reliable example of "economics of superstars" (Rosen, 1981) where a small number of artists represents a large part of the global sales ${ }^{20}$. The

\footnotetext{
${ }^{19}$ As in Rob and Waldfogel (2006), their survey is composed of 500 undergraduate students of a US university

${ }^{20}$ Empirical validation of the so called « stardom effect» is found in Crain and Tollison (2002), Cox and Chung (1994) for music consumption and Cox and Chung (1991) for the publication in the economic literature.
} 
business model of these industries is driven by the success of stars, blockbusters or bestsellers which permit to produce unknown and unprofitable artists. Piracy has forced the model to evolve by allowing the end-users to control for the diffusion and the distribution of cultural contents. As discussed previously, Blackburn (2007) exhibits a positive correlation between the number of copy available on P2P network and the sales of music for unknown artists. There is also a clue in Zentner (2005) that popular artists are more harmed by digital piracy than less popular ones as international repertoires know a larger decrease in sales than country specific repertoires.

Volz (2006) uses an online survey, which gathers responses from 630 participants, to study the probability of usage of an online music service according to its characteristics (cost, recommender system, chat, repertory and music information). The author makes a distinction between demand for the music of artists who appeared in charts (the "stars") and those who do not (the "nonstars"). The result of the conjoint analysis shows that the use of P2P networks is associated with the consumption of less popular music than itunes or virtual communities ${ }^{21}$. The size of the repertoire as well as the possibility to communicate with others users and the gratuitousness of downloads are factors which favour the consumption of nonstars music. These conclusions join those of Dagiral and Dauphin (2005) who have interviewed P2P users and conclude that P2P networks are not only the place where people exchange copyrighted contents but also a space where people communicate and make their tastes evolved.

Gopal et al., (2006) study the consequence of the decrease in sampling cost, which is supposed to be the consequence of digital piracy, on the demand for music. They suggest that high sampling costs favour the "economics of superstars" by hiding the true value of music. Analysing the response of 200 students to a questionnaire relative to their online music consumption, they conclude that the access to file-sharing networks have lowered the cost of information acquisition and generates the discovering of new artists which substitute for superstar's sales. Gopal et al., (2006) also show that the number of different artists and albums in music charts has increase since the development of the Internet, this empirical evidence brings additional support to the claim of global tendency to a reduction of the stars system phenomenon.

\footnotetext{
${ }^{21}$ What the author calls "virtual communities" seems to be social networks dedicated to music like Myspace.
} 


\subsection{Change in the consumption cycle}

Another consequence of the development of information and communication technology on the music and the movie industry comes from the change in the revenue distribution along the life cycle of cultural products. As emphasize by Connoly and Krueger (2005), the income of pop-rock artists mainly comes from live performances while revenue of CD sales is capture by producers and record companies. In this context, piracy has changed the power struggle between artists and producers in support of the formers. This result is underlined by the finding of Mortimer and Sorensen (2005) who suggest that since 1998 the decrease of artists revenues, resulting from the decline in music sales, has been more than offset by the increase in concert revenues. Two reasons seem to explain this result, first if we consider the prevalence of the income effect (as a consequence of the ability to download music for free), then the demand for concert increase. Secondly, the complementary relationship between CD and concert makes people who listen more music, thanks to P2P, more able to buy concert tickets.

This conclusion don't contradict the fact that music industry revenue has decreased last ten years but support an alternative cause than the malice aforethought of P2P users. Piracy is not a disease but a symptom of the change in the way information is acquired and transmitted. Some intermediaries become less important as new information and communication technology allows a more direct matching between artist and audience. As a result the revenue transferred from record company to artist as revealed by Mortimer and Sorensen (2005) appear as a consequence of this major change.

The movie industry has to deal with similar issues, the life cycle of movies follows different sources of releases: theatrical, pay TV, DVD and broadcast TV. Digital piracy disrupt this established order by making high quality movies available on P2P networks before the DVD released and even sometimes during the theatrical run. We can consider that the reduction in the time between theatrical diffusion and DVD release (Nelson, Reid and Gilmore, 2007), the development of catch-up TV services on the Internet or the generalization of worldwide release is the producers and distributors responses to damages made by piracy.

The life cycle of cultural products has also been modified by the emergence of online used goods market. Before the development of the Internet there was no global market for used books, CDs or DVDs. Today Amazon is the main marketplace for used goods and one can ask if this new market is not (or will not be) responsible for a part of the decrease in sales of cultural products. Ghose et al., (2006) have estimated the consequence of used books on sales of new-products in Amazon.com, their findings reveal that only 16\% of used books purchased 
are likely to harm the sellers of new-products. Even if additional studies have to be done concerning the used market of CDs and DVDs it gives another evidence of the change in the consumption cycle of cultural goods and the loss of control incurred by entertainment industry on the distribution process.

A more general remark can be made to resume the impact of the Internet and $\mathrm{P} 2 \mathrm{P}$ networks on the music and video industry. Record company, studios or producers take a risk when they decide to invest money in a project or an artist. According to this fact, industry is conduced to control the way of communication by imposing their editorial policy ${ }^{22}$. The star system phenomenon emerges as the consequence of a rational choice made by investors to minimize the risk by choosing to spend money and pay better attention to popular artist. The risk is inherent to the uncertainly of generating sales and attracting audience. As it is the case for every experience goods, consumer suffers from lake of information about the product he wants to buy which legitimate the role of the industry as a middleman.

The rising of online activities going from participating to an online community to sharing contents in P2P networks has created a new form of intermediation. They permit to collect and process information based on individuals experiences or tastes and play the role of new intermediaries between artist and audience by making recommendation, discovering artist and creating new fashion phenomenon. A number of singers and musicians are first emerging from the Internet "voice of the crowd" ${ }^{\text {"23 }}$ before record companies decide to invest in them ${ }^{24}$. As the success uncertainly is reduced by the ex ante selection of potential consumers the industry still could not be paid for assuming the risk of not meeting audience. As a result there is a strong probability that new business model driven by consumer-mediated devices will offer a more direct relationship between artist and audience weakening the role of industry holders and increasing openness and diversity in the market.

\section{Conclusion}

Since the appearance of Napster, digital piracy is become a major concern for the cultural industries. The theoretical literature has shown that under particular circumstances piracy could be profit and welfare-enhancing but this result has had difficulties to emerge in empirical studies. However the negative relationship between sales of cultural goods and

\footnotetext{
${ }^{22}$ See, for example, Caves (2002) for a discussion on payola, the illegal payment of radio broadcasters by record companies.

${ }^{23}$ This expression is used in Xia et al., (2006) to describe new communication features in online communities

${ }^{24}$ See for instance the story of Colbie Caillat or Arctic Monkeys.
} 
piracy is not so clear and in this review of the empirical literature we give some reasons to think that in addition to piracy others mechanisms contribute to make physical cultural goods less attractive.

1. The use of the rate of the Internet or broadband access penetration as a proxy for the importance of piracy has certainly lead to an overestimation of the impact of illegal file sharing on the revenue of cultural industry. Studies based on micro data or surveys have displayed more contrasted results about the consequence of piracy.

2. The results concerning the movie industry are much more balanced than those of the music industry which suggest two possible explanations. Or there exists specific factors that negatively impact the sale of music without having the same impact on the movie industry, or there is a lag in the consequence of piracy on the movie industry? Liebowitz (2005) as well as Peitz and Waelbroeck (2005) have searched for alternative explanations of the crisis in the music industry. Liebowitz (2005) argues that nor a change in price, income, quality or the supply of music nor the existence of direct substitute as DVD or video games is able to explain the decrease in sales, Peitz and Waelbroeck (2005) bring a different point of view and suggest that at the end of 90's people have finished to replace their vinyl records and cassette tapes by compact disc which could have been a cause of the decrease of CD sales ${ }^{25}$. They also left us to understand that a change in the distribution channel, by favouring the stardom effect could make consumers searching for alternative distribution channel. The role played by direct substitute as DVD is also debated, some elements tend to prove that the rising of the DVD format and the falling of its price could have a negative impact (Peitz and Waelbroeck, 2004, Stevans and Sessions, 2005) while others show that the consumption of DVD and music is complementary (Liebowitz, 2005, Andersen and Frenz, 2008).

3. Even if we admit that piracy is globally detrimental for cultural industries, strong evidences show that it could be locally beneficial for unknown and new artists (the tail of the distribution of sales). As a result piracy forces the business model of cultural industry to evolve toward less concentration of sales, a shift in the distribution of revenue between the actors of the industry and the recognition of the competition with new medias appeared with the rising of the internet.

\footnotetext{
${ }^{25}$ This argument is also emphasized by Bourreau and Labarthe-Piol (2006) in their study of the French music market.
} 


\section{Reference}

Andersen, B., Frenz, M., 2008. The Impact of Music Downloads and P2P File-Sharing on the Purchase of Music in Canada. Working Paper, Department of Management Birkbeck University of London.

Anderson, C., 2006. The Long Tail: Why the Future of Business is Selling Less of More, Hyperion Books.

Awad, N.F., Dellarocas, C., Zhang, M., 2004. Estimating Word-of-Mouth for Movies: The Impact of Online Movie Reviews on Box Office Performance", Workshop on Information Systems and Economics (WISE), College Park, MD.

Banerjee D., Khalid, A. M., Sturm, J-E., 2005. Socio-economic Development and Software Piracy. An Empirical Assessment. Applied Economics 37, pp. 2091-2097.

Besen, S.M., Kirby, S.N., 1989. Private Copying, Appropriability, and Optimal Copying Royalties. Journal of Law and Economics 32, pp. 255-280.

Bezmen T.L., Depken, C.A., 2006. Influences on Software Piracy: Evidence From the Various United States », Economics Letters 90, pp. 356-361.

Blackburn, D., 2007. The Heterogenous Effects of Copying: The Case of Recorded Music. Working paper, Harvard university, Cambridge.

Boorstin, E.S., 2004. Music Sales in the Age of File Sharing. Senior Thesis, Princeton University.

Bounie, D., Bourreau, M., Waelbroeck, P., 2005. Pirates or Explorers? Analysis of Music Consumption in French Graduate Schools", Working paper, Telecom Paris Tech.

Bounie, D., Bourreau, M., Waelbroeck, P., 2006. Piracy and Demands for Films: Analysis of Piracy Behavior in French Universities", Review of Economic Research on Copyright Issues, $3(2)$.

Bourreau, M., Labarthe-Piol, B., 2006. Crise des ventes et téléchargements sur les réseaux peerto-peer : le cas de la France. Réseaux 139, pp. 106-144.

Brynjolfsson, E., Kemerer, C.F., 1996. Network Externalities in Microcomputer Software: An Econometric Analysis of Spreadsheet Market. Management Science 42, pp. 1627-1647.

Brynjolfsson, E., Smith, M.D., Hu, Y., 2003. Consumer Surplus in the Digital Economy: Estimating the Value of Increased Product Variety at Online Booksellers. Management Science 49(11),

Brynjolfsson, E., Hu, Y., Simester, D., 2007. Goodbye Pareto Principle, Hello Long Tail: The Effect of Search Costs on the Concentration of Product Sales. Working paper, Sloan School 
Management.

Caves, R.E., 2002. Creative Industries: Contracts between Art and Commerce. Harvard University Press.

Conner K.R., Rumelt, R.P., 1991. Software Piracy - An Analysis of Protection Strategies. Management Science 37, pp.125-139.

Connolly, M., Krueger, A.B., 2005. Rockonomics: The Economics of Popular Music. Working Paper 11282, National Bureau of Economic Research.

Cox, R.A, Chung, K.H., 1991. Patterns of Research Output and Author Concentration in the Economics Literature. The review of Economics and Statistics 73(4), pp. 740-747.

Cox, R.A, Chung, K.H., 1994. A Stochastic Model of Superstardom: An Application of the Yule Distribution. The review of Economics and Statistics 76(4), pp. 771-775.

Crain, W., Tollison, R., 2002. Consumer Choice and the Popular Music Industry: A Test of the Superstar Theory. Empirica 29(1), pp. 1-9.

Dagiral, E., Dauphin, M., 2005. P2P: From File Sharing to Meta-information Pooling? Communications \& Stratégies 59(3), pp. 35-51.

De Vany, A.S, Walls, W.D., 2007. Estimating the Effects of Movie Piracy on Box-office Revenue. Review of Industrial Organization 30, pp. 291-301.

Duchene, A., Waelbroeck, P., 2006. The Legal and Technological Battle in the Music Industry: Information-push Versus Information-pull Technologies. International Review of Law and Economics 26(4), pp 565-580.

Fetscherin, M., 2004. Movie Piracy on Peer-to-Peer Networks- The Case of KaZaA. Telematics and Informatics 22, pp. 57-70.

Gensollen, M., 2006. La culture entre économie et écologie : l'exemple des communautés en ligne" in Création et diversité au miroir des industries culturelles, Xavier Greffe, ed. La Documentation Française, pp. 285-312.

Ghose, A., Smith, M.D., Telang, R., 2006. Internet Exchanges for Used Digital Goods: An Empirical Analysis of Product Cannibalization and Welfare Impact. Information System Research 17(1), pp.3-19.

Givon, M., Mahajan, V., Muller, E., 1995. Software Piracy: Estimation of Lost Sales and the Impact on Software Diffusion. Journal of Marketing 59, pp 29-37.

Gopal, R. D., Bhattacharjee, S., Sanders, G. L., 2006. Do Artists Benefit from Online Music Sharing. Journal of Business 79(3), 1503-1533.

Hui, K-L., Png , I.P.L., 2003. Piracy and the Legitimate Demand for Recorded Music. 
Contributions to Economic Analysis and Policy 2(1), article 11.

Husted, B.W., 2000. The Impact of National Culture on Software Piracy. Journal of Business Ethics 26, pp. 197-211.

Johnson, W., 1985. The Economics of Copying. Journal of Political Economy 93, pp. 158-174.

Kranenburg, H. V., Hogenbrink, A., 2003. Determinants of Multimedia, Entertainment, and

Business Software Copyright Piracy: A Cross-national Study. Working paper, Maastricht

Research School of Economics of Technology and Organization.

Liebowitz, S., 2008. Testing File Sharing's Impact on Music Album Sales in Cities.

Management Science 54, pp. 852-859.

Liebowitz S., Watt, R., 2006. How best to best ensure remuneration for creators in the market for music? Copyright and its alternatives. Journal of Economic Surveys 20, pp. 513-545.

Liebowitz, S., 2005. Pitfalls in Measuring the Impact of File-sharing on the Sound Recording Market. CESifo Economic Studies 51(2-3), pp. 435-473.

Liebowitz, S., 2007a. Don't Play it Again Sam: Radio Play, Record Sales, and Property Rights. Working paper, University of Texas at Dallas.

Liebowitz, S., 2007b. How Reliable is the Oberholzer-Gee and Strumpf paper on File-Sharing? Working paper, University of Texas at Dallas.

Liebowitz, S.J., 1985. Copying and Indirect Appropriability: Photocopying of Journals. Journal of Political Economy 93, pp. 945-957.

Michel, N., 2006. The Impact of Digital File Sharing on the Music Industry: An Empirical Analysis. B.E. Journals in Economic Analysis and Policy: Topics in Economic Analysis and Policy 6(1), pp. 1-22.

Mortimert, J.H, Sorensen, A., 2005. Supply Responses to Digital Distribution: Recorded Music and Live Performances. Proceedings of the AEA Annual meeting Papers.

Moul, C.C., 2007. Measuring Word of Mouth's Impact on Theatrical Movie Admissions. Journal of Economics and Management Strategy 16(4), pp. 859-892.

Nelson, R.A., Reid, C.E., Gilmore, O., 2007. An Analysis of the Out-of-Market Gap for DVDs in the U.S. Review of Industrial Organization 30(4), pp. 303-323.

Oberholzer-Gee, F., Strumpf, K., 2007. The Effect of File Sharing on Record Sales: An Empirical Analysis. Journal of Political Economy 115, pp 1-42.

Ordover, J A., Willig, R.D., 1978. On the Optimal Provisions of Journals qua Sometimes Shared Goods. The American Economic Review 68, pp. 324-339.

Peitz, M., Waelbroeck, P., 2004. The effect of Internet piracy on music sales: cross-section 
evidence. Review of Economic Research on Copyright Issues 1(2), pp. 71-79.

Peitz, M., Waelbroeck, P., 2005. An Economist's Guide to Digital Music. CESifo Economic Studies 51, pp. 359-428.

Peitz, M., Waelbroeck, P., 2006a. Piracy of Digital Products: A critical Review of the Theoretical Literature”, Information Economics and Policy 18(4), pp 449-476.

Peitz, M., Waelbroeck, P., 2006b. Why the Music Industry May Gain From Free Downloading - The Role of Sampling. International Journal of Industrial Organization 24(5), pp. 907-913.

Png, I.P.L, 2006. Copyright: A Plea for Empirical Research. Review of Economic Research on Copyright Issues 3(2), pp. 3-13.

Rob, R., Waldfogel, J., 2006. Piracy on the High C's: Music Downloading, Sales Displacement, and Social Welfare in a Sample of College Students. Journal of Law and Economics 49(1), pp. $29-62$.

Rob, R., Waldfogel, J., 2007. Piracy on the Silver Screen. Journal of Industrial Economics 55(3), pp. 379-395.

Rosen, S., 1981. The Economics of Superstars. The American Economic Review 71(5), pp. 845-858.

Seung-Hyun, H., 2005. Measuring The Effect of Digital Technology on the Sales of Copyrighted Goods: Evidence from Napster. Working paper, University of Illinois at UrbanaChampaign.

Seung-Hyun, H., 2007. The Recent Growth of the Internet and Changes in Household-level Demand for Entertainment. Information Economics and Policy 19, pp. 304-318.

Smith, M.D, Telang, R., 2006. Piracy or Promotion? The Impact of Broadband Internet Penetration on DVD Sales. Working paper, H. John Heinz III School of Public Policy and Management, Carnegie Mellon University.

Smith, M.D, Telang, R., 2008. Competing with Free: The Impact of Movie Broadcasts on DVD Sales and Internet Piracy. Working paper, H. John Heinz III School of Public Policy and Management, Carnegie Mellon University.

Stevans L.K., Sessions, D.N., 2005. An Empirical Investigation Into the Effect of Music Downloading on the Consumer Expenditure of Recorded Music: A Time Series Approach. Journal of Consumer Policy 28, pp. 311-324.

Takeyama, L.N., 1994. The Welfare Implications of Unauthorized Reproduction of Intellectual Property in the Presence of Network Externalities. Journal of Industrial Economics 42, pp. 155166. 
Takeyama, L.N., 2003. Piracy, Asymmetric Information and Product Quality Revelation. in The Economics of Copyright: Recent Developments and Analysis, Wendy Gordon and Richard Watt, eds., Edward Elgar.

Volz, I. P., 2006. The Impact of Online Music Services on the Demand for Stars in the Music Industry. Working paper, Johann Wolfgang Goethe University.

Waelbroeck, P., 2006. Evolution du marché de la musique préenregistrée à l'ère numérique", Reflets et Perspectives XLV, pp. 83-92.

Xia, M., Huang, Y., Duan W., Whinston, A.B., 2008. Voice of the crowd: ballot box communication in online communities. Working paper.

Zentner, A., 2005. File Sharing and International Sales of Copyrighted Music: An Empirical Analysis with a Panel of Countries. B.E. Journals in Economic Analysis and Policy: Topics in Economic Analysis and Policy 5(1), pp. 1-15.

Zentner, A., 2006. Measuring the Effect of File Sharing on Music Purchases. Journal of Law and Economics 49(1), pp. 63-90. 